
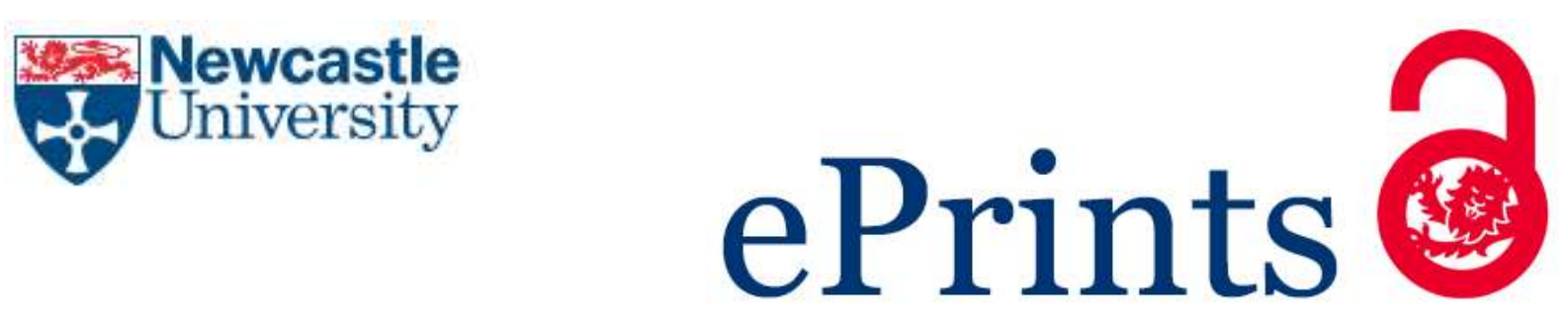

Widmer JD, Martin R, Mecrow BC. Optimisation of an 80kW Segmental Rotor Switched Reluctance Machine for Automotive Traction. IEEE Transactions on Industry Applications 2015, 51(4), 2990-2999.

\title{
Copyright:
}

(C) 2015 IEEE. Personal use of this material is permitted. Permission from IEEE must be obtained for all other uses, in any current or future media, including reprinting/republishing this material for advertising or promotional purposes, creating new collective works, for resale or redistribution to servers or lists, or reuse of any copyrighted component of this work in other works.

DOI link to article:

http://dx.doi.org/10.1109/TIA.2015.2405051

Date deposited:

$24 / 08 / 2015$ 


\section{Optimisation of an 80kW Segmental Rotor Switched Reluctance Machine for Automotive Traction}

\author{
James D. Widmer \\ Newcastle University \\ Newcastle-upon-Tyne \\ NE1 7RU, UK \\ james.widmer@ncl.ac.uk
}

\author{
Richard Martin \\ Newcastle University \\ Newcastle-upon-Tyne \\ NE1 7RU, UK \\ richard.martin2@ncl.ac.uk
}

\author{
Barrie C Mecrow \\ Newcastle University \\ Newcastle-upon-Tyne \\ NE1 7RU, UK \\ barrie.mecrow@ncl.ac.uk
}

\begin{abstract}
There is significant interest in the development of Switched Reluctance Machines for use in automotive traction applications. This has been driven by their low cost compared to rare earth Permanent Magnet based motors, driven by the high cost of rare earth permanent magnets, coupled with their potential for competitive torque densities. This paper describes the development of a variant of the Switched Reluctance Machine, utilising a Segmental Rotor construction, which has previously been demonstrated to provide the potential for significant improvement in torque densities compared to Switched Reluctance Machines with a conventional toothed rotor construction. The paper describes a strategy which has been developed to optimise the Segmental Rotor SRM to maximise efficiency, with the aim of achieving performance equivalent to that of the $80 \mathrm{~kW}$ Interior Permanent Magnet machine utilised in Nissan's LEAF electric vehicle. Optimisation applies a combination of static and dynamic analyses in order to achieve a full and computationally efficient assessment of motor performance across different regions of the torque speed envelope. Test results from a prototype motor are also presented.
\end{abstract}

Index Terms-Optimization methods, Reluctance motors, Traction motors, Energy conversion, Electric machines.

\section{INTRODUCTION}

Switched Reluctance Machines (SRMs) are experiencing a resurgence in interest. In automotive traction applications they demonstrate advantages in terms of cost compared to both rare earth permanent magnet brushless motors and also induction machines [1] whilst also offering the potential for relatively high torque densities [2]. However, concerns have remained due to their larger size and mass compared to rare earth permanent magnet motors, a consideration in all applications and in particular for automotive, as well as their reputation for torque ripple and acoustic noise [3].

This paper presents a design process which leads to the development of an SRM traction motor aimed at closely matching the specification of the Interior Permanent Magnet (IPM) motor based system employed in Nissan's LEAF electric vehicle [4].

Previous research [5-10] has highlighted the potential benefits of the Segmental Rotor SRM. In [11], this machine topology has been shown to have the capability to produce up to $65 \%$ more torque per unit winding loss [11] than a conventional SRM, due to its improved magnetic utilisation. This increased torque density is a result of the characteristic that, with a single phase energised, a larger proportion of stator teeth carry flux than would be the case in a conventional SRM; this is illustrated in Fig. 1. However this also means that the motor is prone to mutual interactions between neighbouring phases, as two phases may link flux through the same tooth at any time instant.
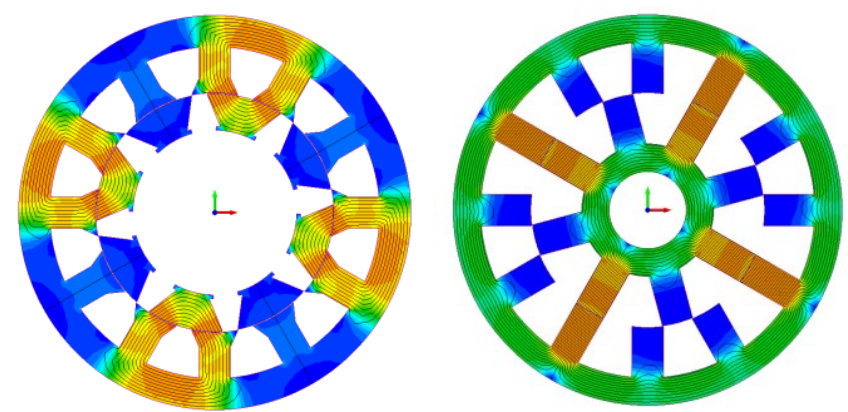

Fig. 1: The Segmental Rotor SRM (left) can be seen to have better magnetic utilisation with twice as many teeth carrying flux at any one time than with a conventional SRM (right). Both machines are shown with rotors in the aligned position and with the same MMF in a single phase. A Segmental Rotor SRM with fully pitched windings is shown.

The authors [11] have previously described an approach which enables the optimisation of these machines, utilising static finite element characteristics to judge the best geometry in order to maximise torque per unit loss. However this technique is limited when optimizing a motor for use in an automotive traction application. Firstly this static method does not readily lend itself to the estimation of dynamic range of the motor in terms of the extents of its torque and speed envelope, this is clearly critical as torque-speed curves frequently form the basis of automotive traction requirements. Secondly static finite element analysis cannot be used to reliably estimate motor iron losses, making a true comparative estimate of motor torque per unit loss and efficiency difficult to achieve. Finally the static optimization 
method does not take into account the above mentioned mutual interaction between phases which is observed in the Segmental Rotor SRM.

It is also clear that the multi-objective optimisation of SRMs will be complicated and time consuming due to their highly non-linear characteristics. High performance SRMs are generally controlled through the use of control maps, setting current advance angles, conduction angles and peak current requirements such that a particular operating point is achieved. These are conventionally calculated using large number of trial and error runs [12]; an approach which cannot be readily applied in a time efficient manner to a complex optimisation.

As a result, this paper outlines a new approach to optimising Segmental Rotor SRMs, a class of machine which has not been frequently assessed. This approach combines both static and dynamic analyses to provide a more complete assessment of the efficiency and performance characteristics of differing motor geometries. To the authors' best knowledge of the literature, this paper proposes a new way of filtering Segmental Rotor SRM motor geometries, as part of a formal optimization, based on their ability to meet certain torque speed requirements. Optimisation uses a combination of static and transient finite element analysis runs with the aim of minimizing the optimization timescales for this class of very non-linear electrical machine.

\section{OPTIMISATION APPROACH}

\section{A. Principles of Optimisation}

The objective of the optimisation described in this paper is to develop a Segmental Rotor SRM which has performance matching closely that of the Nissan LEAF's IPM traction machine [4]; the design objectives are summarized in Table 1. However, to allow a level of design freedom the size of the motor is not limited to that of the Nissan LEAF's electrical machine.

It is acknowledged that the Nissan Leaf's IPM is considerably less torque dense than other electrical machines used for example by Toyota in the Prius and other hybrid electric vehicles, however in those other examples

TABLE 1

SEGMENTAL ROTOR SRM DESIGN OBJECTIVES

\begin{tabular}{|l|c|}
\hline & Value \\
\hline Peak Torque & $280 \mathrm{Nm}$ \\
\hline Peak Power & $80 \mathrm{~kW}$ \\
\hline Base Speed & $2,750 \mathrm{rpm}$ \\
\hline Maximum Speed & $10,500 \mathrm{rpm}$ \\
\hline DC Link Voltage & $400 \mathrm{~V}$ \\
\hline Peak Phase Current & $500 \mathrm{~A}$ \\
\hline Motor Volume & Not Constrained \\
\hline Minimum Airgap Length & $0.3 \mathrm{~mm}$ \\
\hline Slot Fill Factor (Copper) & 0.46 \\
\hline Current Density & Unconstrained \\
\hline
\end{tabular}

Segmental Rotor SRM optimisation is based on the use of a commercially available finite element package using an evolutionary based solver as detailed in [13]. This software allows the comparison of a series of randomly generated geometries, with each geometry assessed through the use of a user defined objective function. Over time, once sufficient data points have been collected, the algorithm narrows the geometric search window in order to identify an optimum solution.

Three objectives were defined for the optimisation of this traction motor. The first objective, illustrated in Fig. 2, is that the motor must achieve the required torque speed characteristic within the constraint of the current and voltage limits set by the power converter. For comparison with the Nissan LEAF, this means achieving $280 \mathrm{Nm}$ at a speed of approximately $2750 \mathrm{rpm}$ for a DC link voltage of circa $400 \mathrm{~V}$ and peak current of circa 500A. No attempt was made to limit current density in motor windings.

The second objective (again, Fig. 2) is that the motor be as efficient as possible at one or more normal operating points. The selection of these motor operating points is based on the predicted time residency of motor operation in different areas of the torque speed characteristic, as estimated through the assessment of the vehicle's driving cycle. In this case, lacking data on the baseline operating points for the Nissan LEAF, a single example operating point of $3500 \mathrm{rpm} / 40 \mathrm{Nm}$ was assumed. This equates to a constant speed of about $35 \mathrm{mph}$, simulating city driving.

The third objective, providing balance to the second, was that the motor's mass should be limited, ensuring that it remains consistent with the motor's use in an electric vehicle.

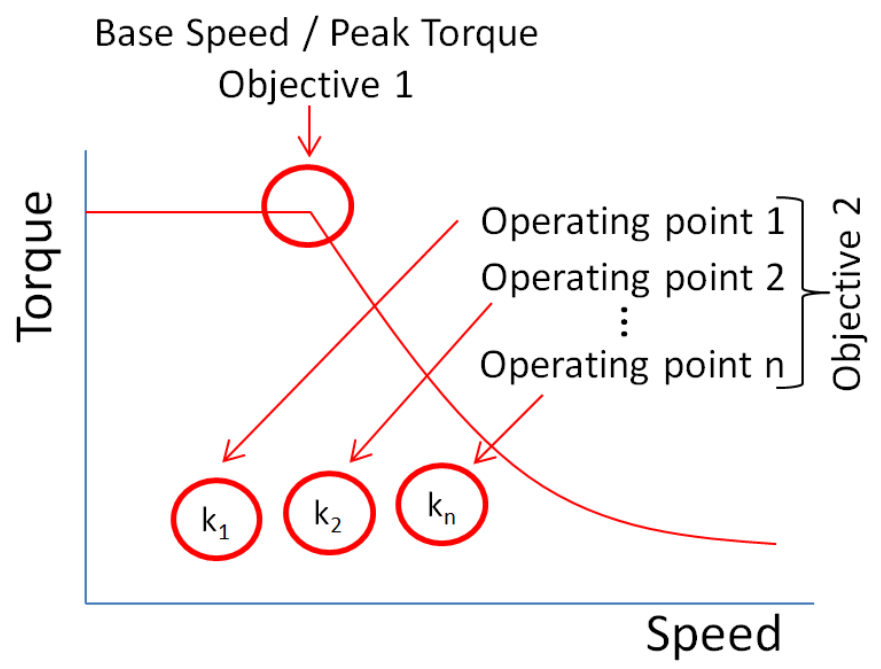

Fig. 2: Showing the key optimisation points for Segmental Rotor SRMs.

\section{B. Objective Function}

In order to compare the success of each step of the motor optimisation, an objective function is defined. In order to consider motor efficiency at each operating point, as well as 
taking into account motor mass, it is necessary to develop a method of equating motor mass to motor efficiency. This is done by defining a scaling constant to the motor mass; in this case $10 \mathrm{~kg}$ motor active mass (being the mass of the rotor laminations, stator laminations and windings) for each percent of motor efficiency was selected; this selection was somewhat arbitrary but considered to be reasonable. A more rigorous approach would be to derive this value from a full vehicle system modelling activity.

The objective function can then be calculated according to the following equation:

$$
\text { Objective Function }=\frac{\sum_{i=1}^{n} k_{i} \cdot \eta_{i}}{n}-k_{\text {mass }} \text {. Mass }
$$

where $n$ is the number of operational points to be assessed, $k_{i}$ the weighting factor for each operating point, $\eta_{i}$ the efficiency at each operating point and $k_{\text {mass }}$ a factor which converts mass into an efficiency equivalent.

\section{Hybrid Optimisation Process}

The optimisation process, summarised in Fig. 3, is a hybrid of static and transient finite element analyses. This process is fully automated through the use of Visual Basic scripts, coupled to the optimisation toolset.

In order to confirm the first objective (achievement of the full torque-speed characteristic), a series of static finite element analyses are undertaken. A static flux linkage characteristic is generated; this is used to set the number of winding turns to allow the achievement of peak torque up to base speed with the available supply current (see Section II.D for full details). The static characteristic is then also used to predict motor torque at base speed; these characteristics form the basis of an assessment of whether sufficient motor flux can be achieved, given the converter's voltage limit, in order to achieve the required power at base speed (see Section II.E).

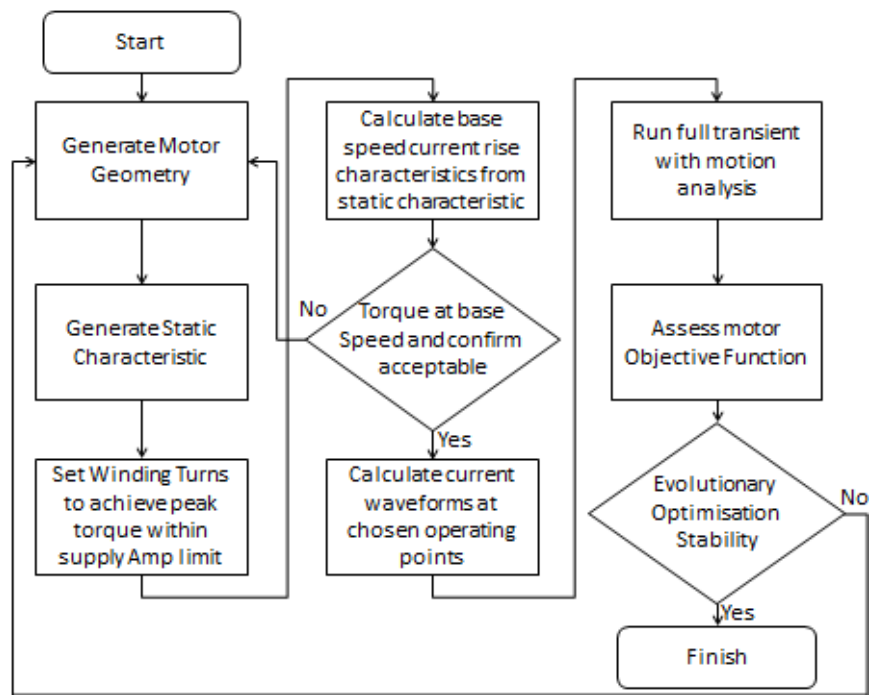

Fig. 3: Proposed optimisation process which makes use of both static and transient finite element analysis techniques.
Should it not be possible to achieve the required base speed / peak torque then the geometry is disregarded and a new geometry generated. If this static analysis demonstrates that base speed / peak torque can be achieved then the optimisation proceeds to the next step.

The optimisation then assesses the second and third objectives, more detail of which is provided in Section II.F. In summary, current waveforms, estimated from the static data collated earlier, are generated for each operating point and used as the basis for a full transient with motion 2D simulation. This allows motor output power along with both copper and iron losses to be estimated, allowing calculation of motor electromagnetic efficiency.

The motor mass is then estimated and the objective function for each candidate geometry calculated; these results are then used by the evolutionary algorithm which will progress until an optimum solution is identified.

\section{Static Dertermination of Number of Turns}

As has been described, static finite element calculations are used to assess each candidate geometry's ability to meet the required torque-speed characteristics. Static solutions are used as they significantly reduce solution time over a transient solution, and also because assumptions may be made which simplify the complex, non-linear behaviour of SRMs.

The first stage of this process is to set the number of winding turns such that the peak motor current, with $500 \mathrm{~A}(\mathrm{pk})$ assumed to be available from the supply, is able to deliver the required average motor torque whilst operating at base speed, assuming voltage control. For an SRM this process is generally complex, requiring a number of transient FE runs in order to set turns and advance angle. This was found to be difficult to automate and time consuming as part of an optimisation. A process was therefore developed which makes a number of assumptions in order to make quick, simplified estimate of the number of turns required using a small number of static point solutions.

In Segmental Rotor SRMs, peak static motor torque may be assumed to be produced at around the mid-point between the aligned and unaligned rotor positions; this is where the rate of change of flux linkage with rotor position is at its highest. A static solution is therefore undertaken, in this rotor position, for various values of MMF with torque values being calculated by the finite element software. These provide an indication of the instantaneous peak torque value which would be achieved when the motor is running.

An estimation must then be made of how these values of peak motor torque scale to average motor torque. Fig. 4 shows a representative characteristic, from finite element analysis, for a Segmental Rotor SRM operating at base speed under voltage control with optimised phase turns and advance angle; here average torque of $278 \mathrm{Nm}$, peak torque of $385 \mathrm{Nm}$, minimum torque $203 \mathrm{Nm}$ and torque ripple of $65 \%$; this level of torque ripple and its asymmetry from the mean is 
representative of results compiled for Segmental Rotor SRMs operating at this point in the torque speed envelope.

This characteristic can therefore be used as the basis for estimating mean torque from peak torque for other motor geometries such that:

$$
T_{\text {peak }}=k_{\text {offset }} \cdot T_{\text {ave }} \cdot\left(1+\frac{k_{\text {ripple }}}{2}\right)
$$

where $T_{\text {peak }}$ is the required peak motor torque assuming that $T_{\text {ave }}$ is the desired average torque, $k_{\text {ripple }}$ the torque ripple as a decimal and $k_{\text {offset }}$ is a constant specifying the asymmetry of maximum and minimum torque around the average. For the case shown in Fig. 4, $k_{\text {ripple }}$ would be 0.65 and $k_{\text {offset }} 1.05$, again representative of these machines operating at this torque and speed.

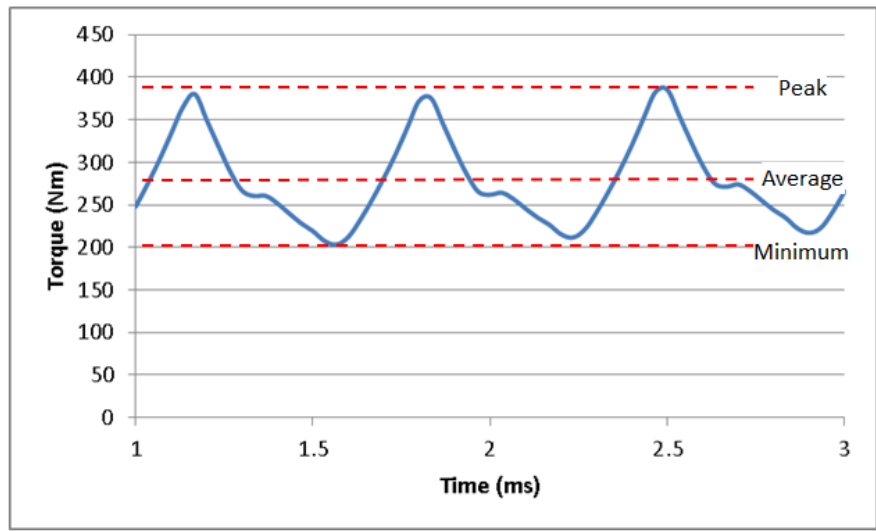

Fig. 4: Representative torque waveform at base speed, peak torque assuming voltage control, optimised winding turns and advance angle.

As a target average torque of $280 \mathrm{Nm}$ is required, it can then be calculated that a peak torque of at least $390 \mathrm{Nm}$ will be required. In order to provide an allowance for motor build effects, a factor of 1.05 is applied to this value, resulting in a target peak torque of $410 \mathrm{Nm}$.

As the peak converter current is known to be $500 \mathrm{~A}(\mathrm{pk})$, it is then straightforward to set the turns number such that turns are minimised whilst still allowing a peak instantaneous torque of at least $410 \mathrm{Nm}$ to be achieved for less than $500 \mathrm{~A}(\mathrm{pk})$ phase current.

\section{E. Static Prediction of Current Rise}

The objective of the next stage of the process is to estimate whether instantaneous peak torque $(410 \mathrm{Nm})$ and hence average torque $(280 \mathrm{Nm})$ and peak power $(80 \mathrm{~kW})$ can be achieved within the available supply VA rating at base speed (2750rpm); simplistically whether it is possible to achieve full phase current (500A) by applying full supply volts $(350 \mathrm{~V})$ at base speed (2750 rpm).

To make this assessment, the static characteristic in the peak torque position is again calculated. Assuming the number of winding turns derived in the previous step, phase current is increased in steps between zero and 500 amps and flux linkage and torque recorded from the finite element software. In order to allow for end winding inductance in a real 3D machine, peak torque position flux linkages are scaled by $115 \%$ in order to simulate this effect.

This data then provides a mapping between phase current, flux linkage and motor instantaneous peak torque. As the instantaneous peak torque required to achieve the desired average motoring torque has been estimated in Section II.D, this can be used to identify the flux linkage that would be required in order to achieve this average torque.

In using this data to calculate whether this level of flux linkage is achievable at base speed, an advance angle of 90 electrical degrees is assumed, meaning that voltage would first be applied with the rotor positioned 180deg in advance of the peak torque position. Equally a conduction angle of $180 \mathrm{deg}$ is assumed, meaning that full supply volts (in this case $350 \mathrm{~V}$ ) would be applied across this electrical angle, with flux peaking at the rotor position giving peak torque.

By using the simple relationship:

$$
\varphi=v \cdot t
$$

(where $\varphi$ is the flux linkage, $v$ the voltage applied to the phase and $t$ the period over which that voltage is applied) it is trivial to calculate whether at a given motor speed there is sufficient time for the flux linkage, and therefore phase current, to climb to the level required.

As a result it is possible to use this analysis to confirm whether the motor could achieve base speed, peak torque by ascertaining whether it would be possible to produce sufficient flux linkage, given available DC link volts, in order to deliver the required torque.

For each optimisation run this test is therefore used to either select, if peak torque could be achieved, or reject a particular geometry prior to moving onto the next stage of optimisation.

\section{F. Dynamic Assessment of Motor Losses}

Once it is established that a motor geometry is able to achieve peak torque at base speed, the next step in the optimisation process is to undertake a transient $2 \mathrm{D}$ finite element simulation in order to calculate losses at the selected operating points.

For SRMs, a high fidelity assessment would be onerous, requiring that, for each operating point, an optimum advance angle be selected and that a current control scheme to be implemented. An alternative is to use a simple trapezoidal current source to approximate such a current control scheme. However it is important that a reasonable approximation of current rise and fall is made so that iron loss calculations remain realistic.

In order to simplify this process, a current rise estimation approach, similar to that applied previously, is used to develop a representative current waveform, shown in Fig. 5.

The required current to achieve the necessary torque is again estimated from the static torque assessment, 
considering once more the likely relationship between peak and average torque.

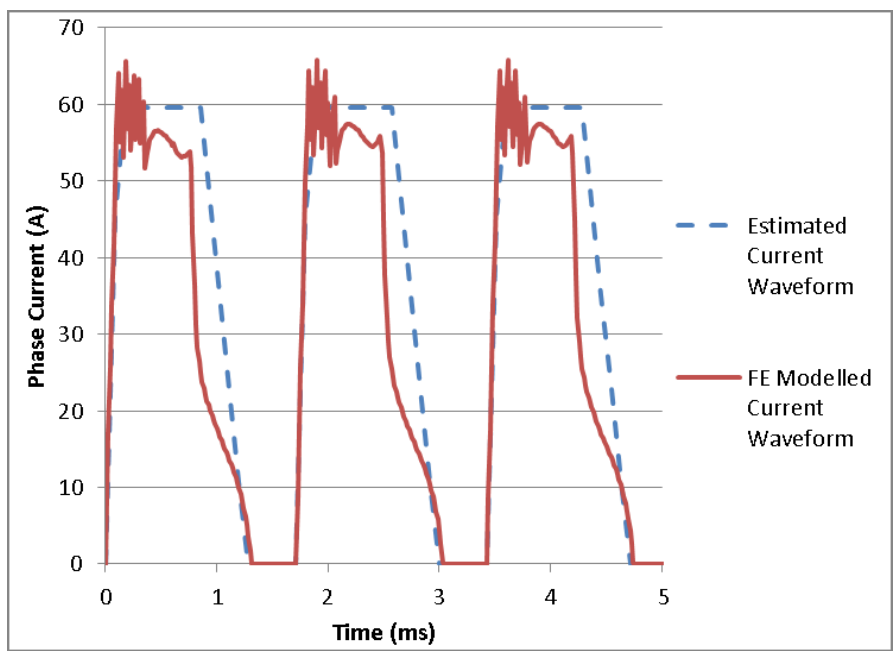

Fig. 5: Comparing the estimated current waveform for the dynamic assessment of motor losses and a full, PI current control waveform.

The current waveform assumes that it is centred on peak torque position, with zero degree advance angle and that conduction angle is 180deg. Static flux linkage / current characteristics can again be used in order to provide an estimate of current rise time. A static flux linkage / current characteristic is calculated in the unaligned position and the existing characteristic for the peak torque position reused. Whilst it would perhaps be better to also calculate the flux linkage / current characteristic at several other electrical angles, this would increase solution time and is not found to significantly improve the fidelity of the operation (see Section V). Instead these characteristics are estimated as a simple linear extrapolation of the other flux linkage data points in the unaligned and peak torque positions.

These static characteristics are then used to estimate flux linkage for the required phase current around the unaligned position, where current will rise, and around the aligned position, where it will fall. Again equation (3) is used as the basis of this calculation, allowing the calculation of current rise and fall times, used to generate an estimated current waveform.

These waveforms are used as the basis of a transient with motion 2D finite element analysis of the motor operating at the required operating points. Copper and Iron losses are estimated and motor efficiency calculated. Finally the objective function is calculated and each geometry compared.

\section{OPTIMISATION SETUP}

A single topology of Segmental Rotor SRM is considered, comprising 12 stator slots, 10 stator poles and alternately wound teeth (see Fig. 6). Only this topology was considered as, with this class of machine, the number of allowable stator tooth and rotor segment combinations is limited. For a 3 phase single tooth wound machine, only combinations of either 6.x-5.x (indicating 6.x Stator Slots and 5.x Rotor Segments) or $6 . x-7 . x$ series, with $x$ being a positive, even, integer number, are possible [11]. This is due to geometrical limitations relating to the rotor geometry and other factors. For example, the ten segment rotor is a practical minimum to avoid unbalanced magnetic pull. In the case of a 10,500 rpm machine, rotor segment numbers are further limited by electrical frequency. A 10 segment machine has a maximum electrical frequency of $1.75 \mathrm{kHz}$ at $10,500 \mathrm{rpm}$; with a converter operating at a maximum switching frequency of

TABLE 2

COMPARISON OF SEGMENTAL ROTOR SRM DESIGNS RESULTING FROM OPTIMISATION AND THE NISSAN LEAF'S IPM MACHINE [4].

\begin{tabular}{|c|c|c|c|c|c|c|c|c|c|}
\hline & 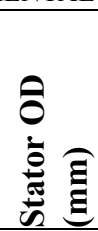 & 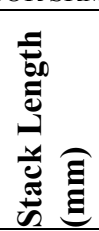 & 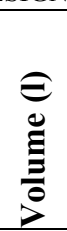 & 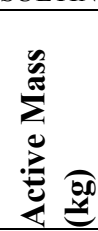 & 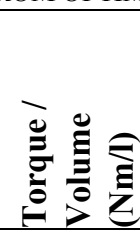 & 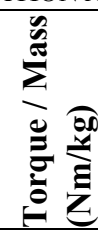 & 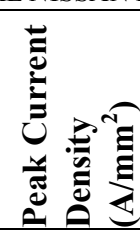 & 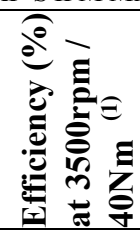 & 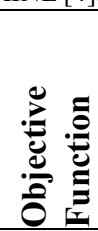 \\
\hline SRSRM1 & 241.4 & 151.5 & 6.9 & 28.4 & 40.6 & 9.9 & 21.7 & 97.5 & 94.7 \\
\hline SRSRM2 & 229.6 & 136.4 & 5.6 & 25.2 & 50.0 & 11.0 & 30.4 & 97.3 & 94.8 \\
\hline SRSRM3 & 191.0 & 241.9 & 6.9 & 30.8 & 40.6 & 9.1 & 26.1 & 97.2 & 94.1 \\
\hline SRSRM4 & 246.2 & 159.1 & 7.6 & 32.8 & 36.8 & 8.5 & 17.2 & 97.3 & 94.0 \\
\hline SRSRM5 & 250.0 & 155.2 & 7.6 & 29.5 & 36.8 & 9.5 & 19.3 & 97.5 & 94.6 \\
\hline Nissan Leaf IPM & 200.4 & 151.5 & 5.7 & 32.0 & 49.1 & 8.8 & $\begin{array}{l}\text { Not } \\
\text { Known }\end{array}$ & 97 & 93.8 \\
\hline
\end{tabular}

(1) Efficiencies include winding loss and iron loss. The Efficiency of the Nissan Leaf is derived from [4] which shows drive efficiency to be $\sim 92 \%$ at this operating point. Motor efficiency is therefore calculated by assuming inverter efficiency of $96 \%$ (calculated using a representative time stepping inverter loss model) and friction / windage of circa 1\%, based on measurements for similar motors. 
$10 \mathrm{kHz}$, consistent of that in commercial inverters operating at this power rating, this would mean each minimum switching period would equate to 16.5 electrical degrees at base speed and more than 63.0 electrical degrees at full speed. Whilst it is possible to use single pulse control at higher speeds, it is also useful to be able to apply current control techniques at lower torques or where continuous current control is applied, in order to achieve fine torque control. These relatively large switching periods would therefore lead to difficulties in achieving accurate current control at high speeds and low torque operating points, where current control is still required. As a result motors with more than 10 segments were ruled out. This decision was also reinforced by the expectation that a machine with a higher pole number would have increased iron losses, as was previously highlighted in [11].

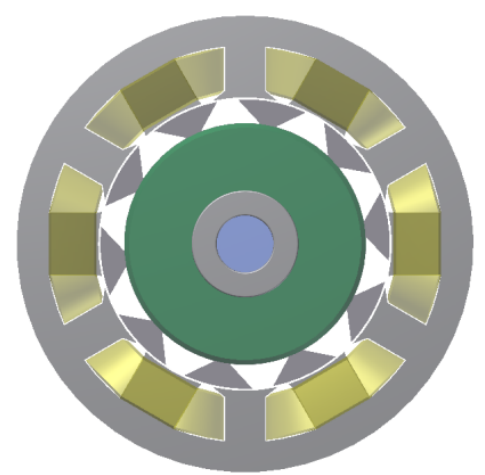

Fig. 6: A 12-10, single tooth would Segmental Rotor SRM.

A parameterised, half model of the 12-10 motor is generated (for example see Fig. 9) such that all motor dimensions may be varied continuously. Basic design rules are applied in accordance with $[5,11]$. These include that, for example, the gap between stator tooth tips be equal to the gap between rotor segment tips and that the rotor segment must have the same span as each stator tooth tip. No limitations are placed on motor outer diameter or length, with it being expected that the mass penalty function would limit total motor volume. Limitations are however placed on minor motor dimensions to avoid the creation of geometries where, for example, stator slots become closed or which are otherwise impractical.

\section{OPTIMISATION RESULTS}

Table 2 presents the results of a series of five optimisation runs and contrasts them with the performance of the IPM motor from Nissan's LEAF electric vehicle.

The results of the optimization show that, when compared based on the single normal operating point (see Section II.A), all of the optimized SRMs offer better objective functions than that of the Nissan Leaf. However given the narrow scope of the optimization, such a comparison is not completely valid.

The Nissan Leaf IPM motor is more compact than all but one of the Segmental Rotor SRMs, though most of the optimised Segmental Rotor SRMs have a lower mass. This is due to the low mass of the segmental rotor, which has small electrical steel laminations embedded in an aluminium core, compared to IPM rotor and to the use of single tooth windings in the SRMs as opposed to heavier distributed windings in the Nissan Leaf IPM.

In one case, SRSRM2, a motor that is both volumetrically smaller and lighter than that used in the Nissan LEAF was predicted. However, as will be seen in Section VI, the development of this design into a practical prototype results in its performance becoming marginal when compared to the requirement to match the performance of the Nissan LEAF's machine. It is in fact the largest and heaviest of the resulting, optimised machines (SRSRM4) which is eventually selected for prototype manufacture (see section VI for details).

It is interesting to note that whilst each optimisation run produces a similar objective function, outer dimensions differ significantly due to the randomness of the optimisation process. This suggests that the optimisation 'surface' is relatively flat. Despite the simplifications applied to the optimisation approach, optimisation runs took between 5 and 15 days to converge.

\section{FINITE ELEMENT VALIDATION OF OPTIMISATION}

The SRSRM2 design is selected as the basis of a study validating the performance of the optimisation process and assumptions described in Section II. Two operating points are considered; firstly base speed, peak torque, validating the current rise modelling and secondly confirmation of losses at the chosen optimisation operating point.

For the former to be valid, the current rise would need to be sufficient to allow the optimised machine to produce the required output power / torque. $2 \mathrm{D}$ finite element analysis is undertaken to confirm this. Based on voltage source PWM, with 'bang-bang' current control, the analysis assumes that the motor is running with 75 degree advance angle (chosen to maximise torque), with 180degree conduction period and under current control.

The results of this analysis are summarised in Table 3. Current and Torque graphs are shown in Fig. 7 and Fig. 8 respectively with a flux density plot of the motor being shown in Fig. 9.

A higher average torque was predicted by the detailed finite element model than that predicted during the optimisation process. This is consistent with the optimisation objective, which is to ensure that the optimised motor has a margin of performance when modelled in $2 \mathrm{D}$, allowing for $3 \mathrm{D}$ and other build effects. However peak torque is found to be less than predicted; this is because the combination of 90 degree advance angle and 180 degree conduction angle led to significant levels of instantaneous negative torque in each phase, as shown in Fig. 8. Further adjustment of advance and conduction angles would be expected to reduce this effect. 
The second test was to compare the results for the selected operating point $(3500 \mathrm{rpm}, 40 \mathrm{Nm})$ used during the optimisation process with a full PWM based current control simulation in 2D FE. The results of this analysis are shown in Table 4. Winding losses are calculated on the assumption that the windings will be operating at a temperature of $150 \mathrm{degC}$, consistent with the motor in continuous operation; end winding resistances are also considered in the winding loss calculations. Iron losses are calculated using a commercial finite element package with a scaling factor of 1.6 applied to allow for build effects [14].

TABLE 3

COMPARING THE RESULTS OF BASE SPEED PEAK TORQUE (2750RPM, 280NM) FROM ESTIMATES DURING OPTIMISATION AND FULL 2D FE.

\begin{tabular}{|l|c|c|}
\hline & $\begin{array}{c}\text { Estimate from } \\
\text { Optimisation }\end{array}$ & $\begin{array}{c}\text { Results from 2D } \\
\text { FE }\end{array}$ \\
\hline Average Torque & $280.0 \mathrm{Nm}$ & $295.7 \mathrm{Nm}$ \\
\hline Peak Current & $494.9 \mathrm{~A}$ & $509.6 \mathrm{~A}$ \\
\hline $\begin{array}{l}\text { Time for Current } \\
\text { to rise to Peak }\end{array}$ & $933.5 \mu \mathrm{s}$ & $927.3 \mu \mathrm{s}$ \\
\hline Peak Torque & $409.3 \mathrm{Nm}$ & $383.7 \mathrm{Nm}$ \\
\hline
\end{tabular}

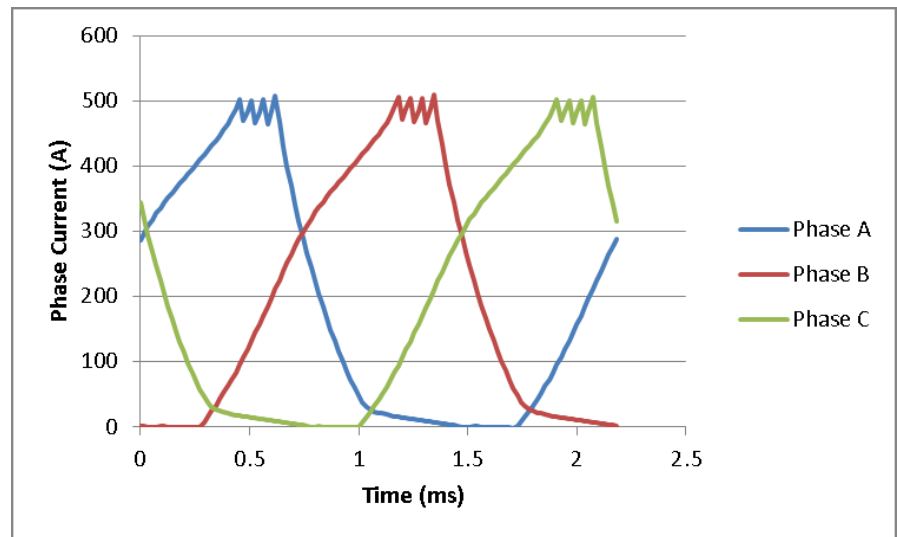

Fig. 7: Phase current waveforms for motor at base speed / peak torque.

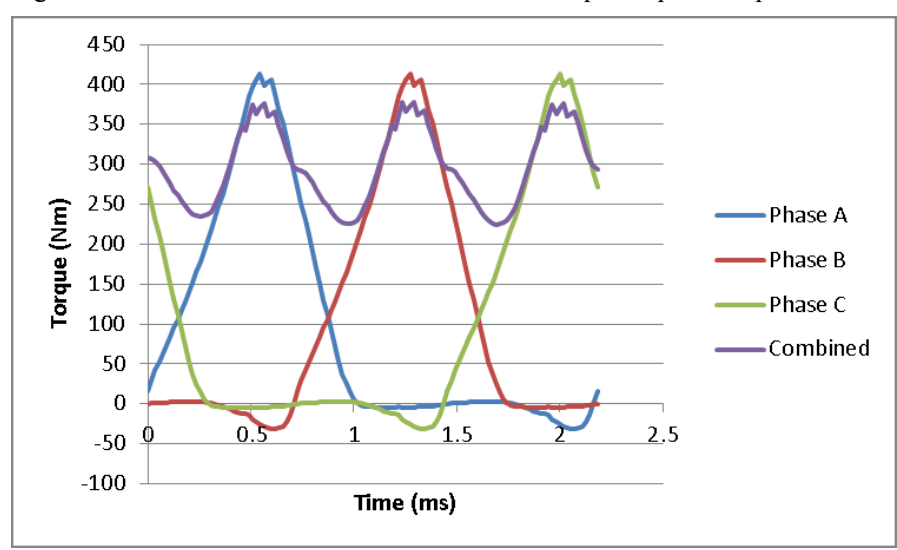

Fig. 8: Torque characteristic for motor operating at base speed / peak torque.

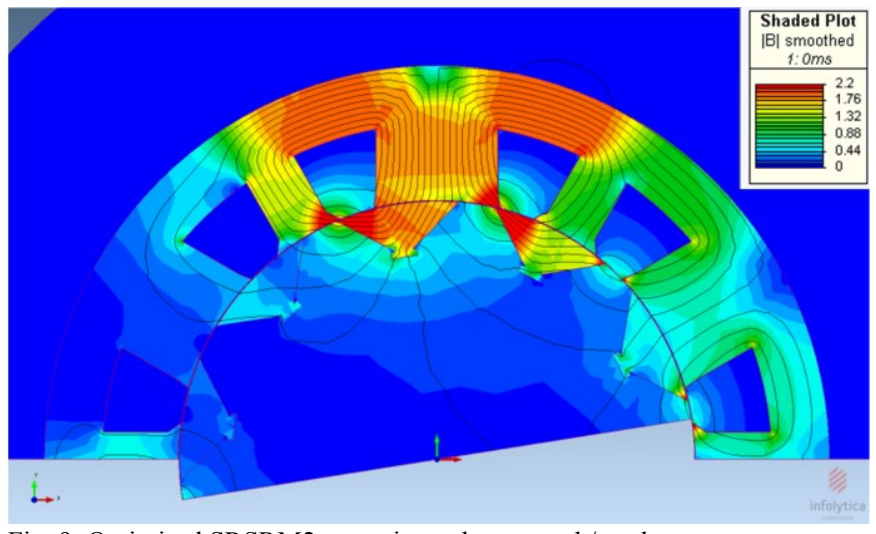

Fig. 9: Optimised SRSRM2 operating at base speed / peak torque.

TABLE 4

COMPARING THE RESULTS OF ANALYSIS OF MOTOR PERFORMANCE AT 3500RPM / 40NM FROM THE OPTIMISATION PROCESS AND FULL 2D FE ANALYSIS.

\begin{tabular}{|l|c|c|}
\hline & $\begin{array}{c}\text { Estimate from } \\
\text { Optimisation }\end{array}$ & $\begin{array}{c}\text { Results from 2D } \\
\text { FE }\end{array}$ \\
\hline Speed & $3500 \mathrm{rpm}$ & $3500 \mathrm{rpm}$ \\
\hline Average Torque & $38.9 \mathrm{Nm}$ & $36.6 \mathrm{Nm}$ \\
\hline $\begin{array}{l}\text { Mechanical } \\
\text { Power }\end{array}$ & $14.3 \mathrm{~kW}$ & $13.4 \mathrm{~kW}$ \\
\hline RMS Current & $39.9 \mathrm{~A}$ & $38.6 \mathrm{~A}$ \\
\hline Winding Loss & $168.3 \mathrm{~W}$ & $157.8 \mathrm{~W}$ \\
\hline Iron Loss & $234.7 \mathrm{~W}$ & $344.1 \mathrm{~W}$ \\
\hline Total Loss & $403.0 \mathrm{~W}$ & $501.8 \mathrm{~W}$ \\
\hline Efficiency & $97.3 \%$ & $96.4 \%$ \\
\hline
\end{tabular}

A number of other factors also need to be taken into account: these include 3D effects, changes made to the motor geometry in order to make it manufacturable and resulting thermal considerations.

As has been discussed earlier, 3D effects will have a significant impact on the base speed / peak torque capability of the motor. A static, 3D FE analysis has been undertaken which showed that 3D effects would increase inductance in both the aligned and unaligned positions by approximately $14 \%$, confirming the assumptions made during optimisation. Whilst this effect is allowed for in the motor optimisation process, there remains a risk that in a practical machine the current required to achieve peak torque would be increased whilst simultaneously the rate of current rise would be reduced sufficiently to limit base speed torque.

It was necessary to modify the design of the rotor segment root in order to allow the rotor to be sufficiently robust to operate at $12,500 \mathrm{rpm}$, which includes a circa $20 \%$ overspeed allowance over the 10,500rpm rated speed. The revised segment root design is shown in Fig. 10. The development of this root will be addressed in more detail in a future paper, however in summary a fir tree root based design [15] was implemented, with electrical steel rotor segments being embedded into an aluminium rotor support. 


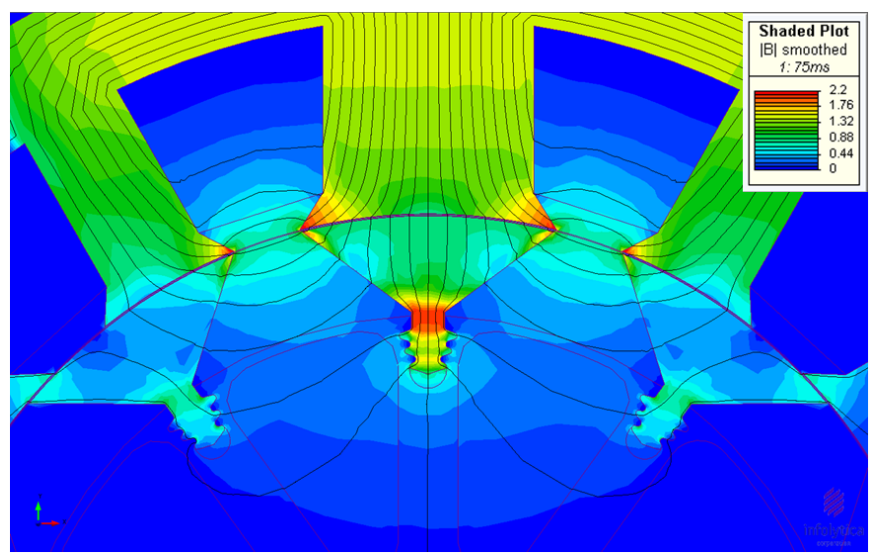

Fig. 10: Fir Tree Root based Rotor segment fixture, showing leakage flux between rotor segments in the unaligned position.

The aluminium rotor support was constructed of insulated aluminium laminations in order to minimise eddy current losses. The revised rotor segment root design resulted in an increase in unaligned inductance of $10 \%$, due to increase leakage between the now larger segments, impacting both absolute motor torque capability per unit loss and also increasing the current rise time constant, limiting torque production at base speed.

Finally, thermal considerations are expected to limit the continuous and short term operation of these electrical machines. Modified as discussed above, the SRSRM2 motor design would produce losses in the order of $14 \mathrm{~kW}$ at base speed and peak torque. This has been found to be too high through thermal modelling, with windings experiencing a steady state temperature rise of greater than $150 \mathrm{degC}$. As a result the motor would have to be de-rated and therefore would not provide performance comparable to that fitted to the Nissan LEAF.

As a result the SRSRM2 motor design was considered to be too marginal for construction as a prototype. Instead the SRSRM4 was selected; Fig. 11 and Table 5 contrast this design with the smaller SRSRM2 design. This machine was found to have significantly lower copper losses, with less than $8 \mathrm{~kW}$ predicted at base speed and peak torque. Thermal modelling suggested this would be acceptable, making the SRSRM4 machine a more credible candidate for prototype construction.

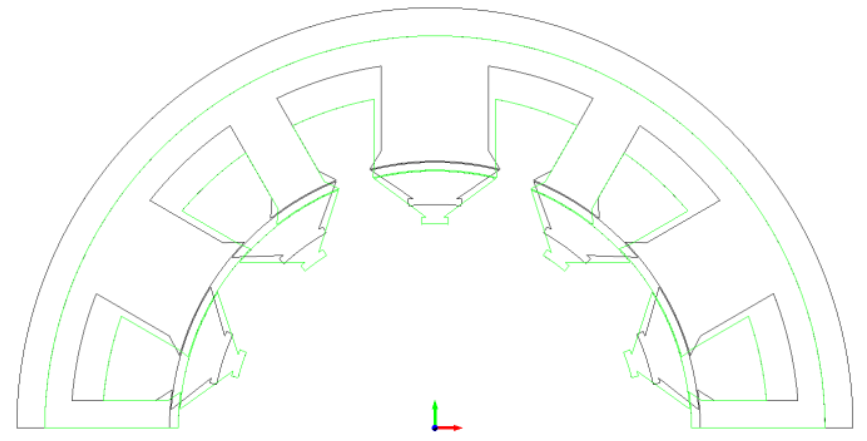

Fig. 11: Comparing the lamination profiles of the two optimised machines, SRSRM2 (grey outline) and SRSRM4 (black outline).
TABLE 5

COMPARING BASE SPEED / PEAK TORQUE PREDICTIONS BETWEEN TWO OPTIMISED MACHINES, FOLLOWING DETAILED DESIGN MODIFICATIONS.

\begin{tabular}{|l|c|c|}
\hline & SRSRM2 & SRSRM4 \\
\hline Speed & $2750 \mathrm{rpm}$ & $2750 \mathrm{rpm}$ \\
\hline Average Torque & $260.3 \mathrm{Nm}$ & $285.8 \mathrm{Nm}$ \\
\hline $\begin{array}{l}\text { Mechanical } \\
\text { Power }\end{array}$ & $75.0 \mathrm{~kW}$ & $82.3 \mathrm{~kW}$ \\
\hline $\begin{array}{l}\text { Winding } \\
\text { Configuration }\end{array}$ & $\begin{array}{c}\text { Alternate teeth wound with single tooth } \\
\text { concentrated coil / } \\
\text { Number of Turns }\end{array}$ & \multicolumn{2}{|c|}{2 series coils per phase } \\
\hline Numds in Hand & 7 & 21 \\
\hline Strands & $1.1 \mathrm{~mm}$ & $1.1 \mathrm{~mm}$ \\
\hline $\begin{array}{l}\text { Bare Strand } \\
\text { Diameter }\end{array}$ & $280.8 \mathrm{~A}$ & $268.4 \mathrm{~A}$ \\
\hline RMS Current & $29.3 \mathrm{~A} / \mathrm{mm}^{2}$ & $16.6 \mathrm{~A} / \mathrm{mm}{ }^{2}$ \\
\hline Current Density & $13,747.5 \mathrm{~W}$ & $7,357.5 \mathrm{~W}$ \\
\hline Winding Loss & $923.8 \mathrm{~W}$ & $907.6 \mathrm{~W}$ \\
\hline Iron Loss & $14,671.2 \mathrm{~W}$ & $8,265.1 \mathrm{~W}$ \\
\hline Total Loss & $83.6 \%$ & $90.9 \%$ \\
\hline Efficiency & $46.5 \mathrm{Nm} / 1 /$ & $37.6 \mathrm{Nm} / 1 /$ \\
\hline $\begin{array}{l}\text { Torque Density } \\
\text { (stack only / with } \\
\text { end windings) }\end{array}$ & $31.2 \mathrm{Nm} / 1$ & $27.0 \mathrm{Nm} / 1$ \\
\hline
\end{tabular}

The levels of torque density reported in Table 5 do not, on first inspection, compare favourably with rare earth magnet free machines reported by other authors, in papers such as $[16,17]$; however this is perhaps unsurprising due to the optimisation strategy applied in this paper. The Segmental Rotor SRMs presented in this paper have in contrast not been optimised for maximum torque density, instead being optimised to achieve high efficiency at a representative high residency operating point. This is illustrated by the relatively low current density in the SRSRM4 machine at base speed, coupled with the high predicted efficiency at the representative operating point, as presented in Table 4.

\section{EXPERIMENTAL VALIDATION}

A prototype motor was therefore constructed, based on the SRSRM4 design summarised in Table 5. Fig. 12 shows the motor frame when compared to IPM traction motor from Nissan's LEAF electric vehicle. The Segmented Rotor SRM is shown on test in Fig. 13.

In order to match available test rig capabilities, the prototype was wound for use with a $500 \mathrm{~V}$ DC Link, rather than the $350 \mathrm{~V}$ used by the Nissan LEAF. Peak current was therefore reduced from $500 \mathrm{~A}$ to $350 \mathrm{~A}$, retaining the same $\mathrm{kVA}$ rating as the LEAF's motor.

A primary method of validating the performance envelope of an SRM, whether that be of conventional or segmental rotor type, is through the generation of magnetisation characteristics for the motor at a series of different rotor angles [12]. 


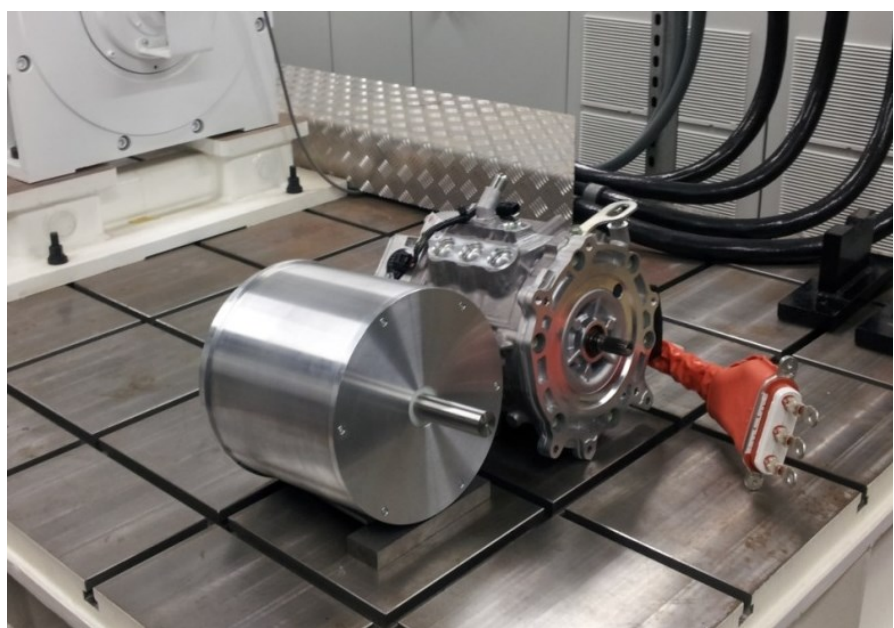

Fig. 12: Showing the resulting Segmental Rotor SRM frame alongside the Nissan's IPM Motor used in the Nissan LEAF.

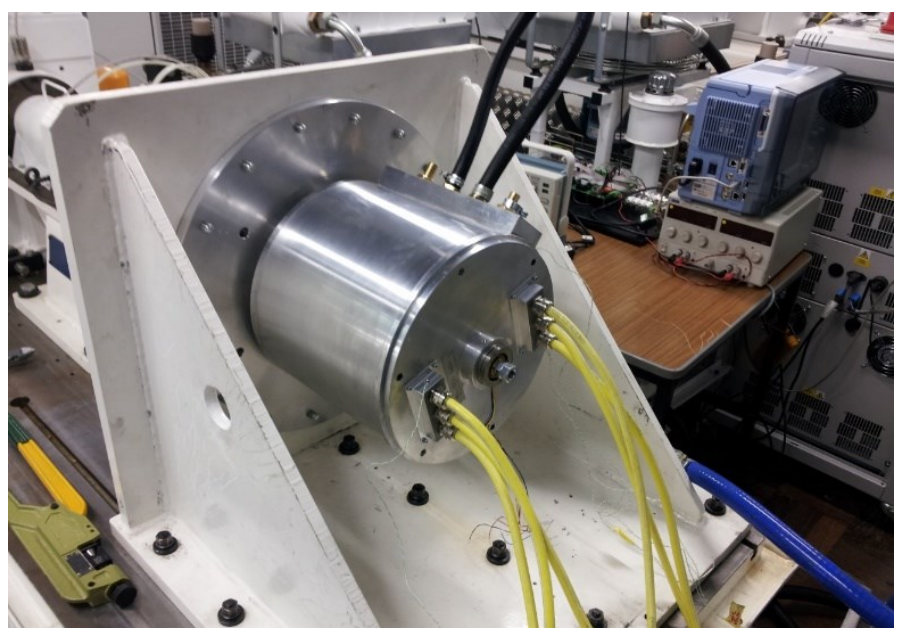

Fig. 13: Showing the prototype $80 \mathrm{~kW}$ Segmental Rotor SRM installed on the test rig.

Static testing was therefore undertaken on the prototype motor to generate this test data, with the results in Fig. 14. These test results are then compared to modelling predictions, from the optimiser, in Fig. 15. A comparison of the resulting, average torque capability of the optimised and constructed motors, calculated from motor coenergy, is shown in Fig. 16; in both cases the torque data is calculated from the collated static flux data, again in accordance with the procedure outlined in [12].

As can be seen the test motor performance was reduced compared to that predicted during optimisation, the motor requiring $42 \%$ higher phase current than had been predicted during optimisation to achieve rated torque $(280 \mathrm{Nm})$. However, as has been discussed earlier in this paper, this reduction in performance was anticipated and the optimised machine would still be capable of producing the required $280 \mathrm{Nm}$ rated torque within the current limit. There are three independent reasons for the reduction in motor performance as follows:

As has been previously shown in [11], 3D effects, due in particular to end-winding leakage flux, have the effect of increasing unaligned inductance. Whilst this also leads to an increase in aligned inductance, this effect is less pronounced due to saturation. In terms of impact of these 3D effects on motoring torque capability, in this design it is found to be a significant influence, increasing phase current required to achieve rated torque by $18 \%$. During the design process this had been anticipated, with a $14 \%$ increase in phase current predicted through 3D finite element modelling and this matching well with the $15 \%$ correction factor applied during optimization (see Section II.E). The increase in motor flux required to achieve a given torque would also have an effect on the running performance of the motor, with the higher current being more difficult to achieve within a limited DC link voltage, potentially limiting motor output power. It is therefore concluded that in future optimisations it would be essential to consider how better to model these effects.

Secondly the material properties assumed for the electrical steel used in construction (M270-35A) and those observed in the prototype were found to be different with, at saturation, a $2 \%$ reduction in flux levels compared to those predicted. Whilst this seems a small difference, it can be shown to result in an increase in phase current of $16 \%$ in order to achieve rated torque. This highlights an area of further development when considering these motors for use in volume production; the potential that small variations in material properties can lead to large variations in motor performance is of concern and would need to be addressed.

Finally, as discussed in Section V, in order for the motor to be sufficiently mechanically robust a high operating speeds, modifications were made to the rotor segment root which had the effect of increasing leakage flux in the rotor unaligned position. This effect was responsible for increasing phase current to achieve rated torque by $8 \%$. This increase in the size of the rotor segment root is a factor which can be straightforwardly accommodated in future optimisations.

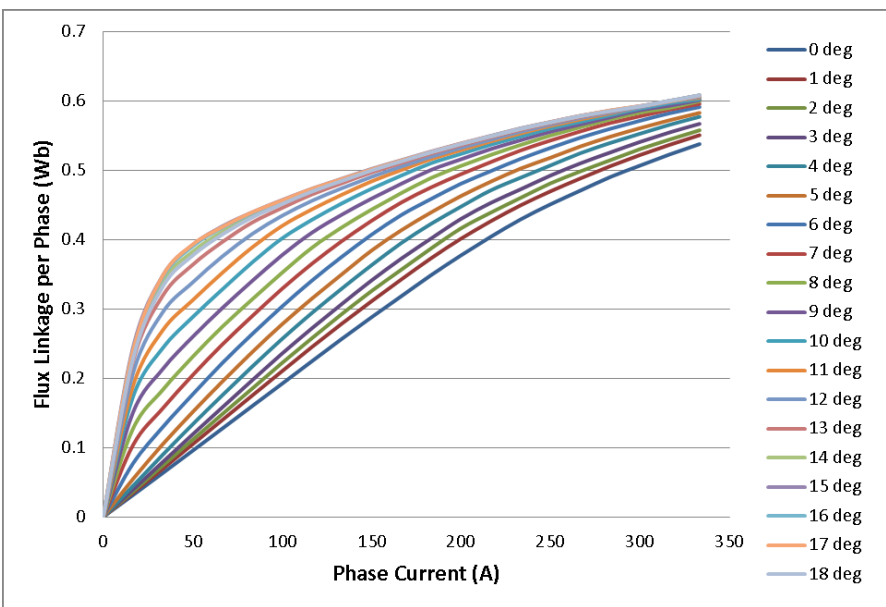

Fig. 14: Full Flux Linkage vs Phase Current and Rotor Angle for the Prototype 80kW Segmental Rotor SRM. 


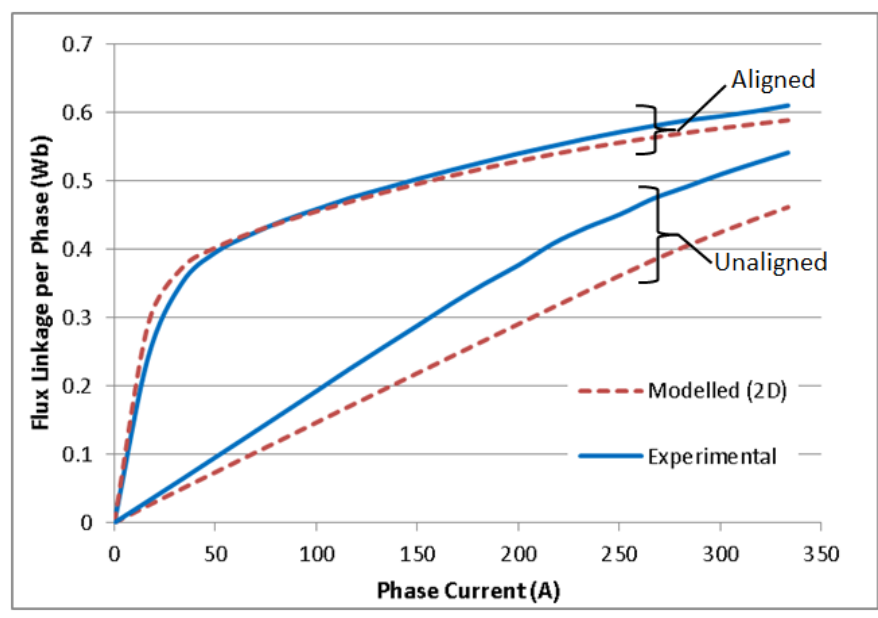

Fig. 15: Comparing Flux Linkage vs Current in the Aligned and Unaligned Positions for the Prototype Motor and from the Optimiser (SRSRM4).

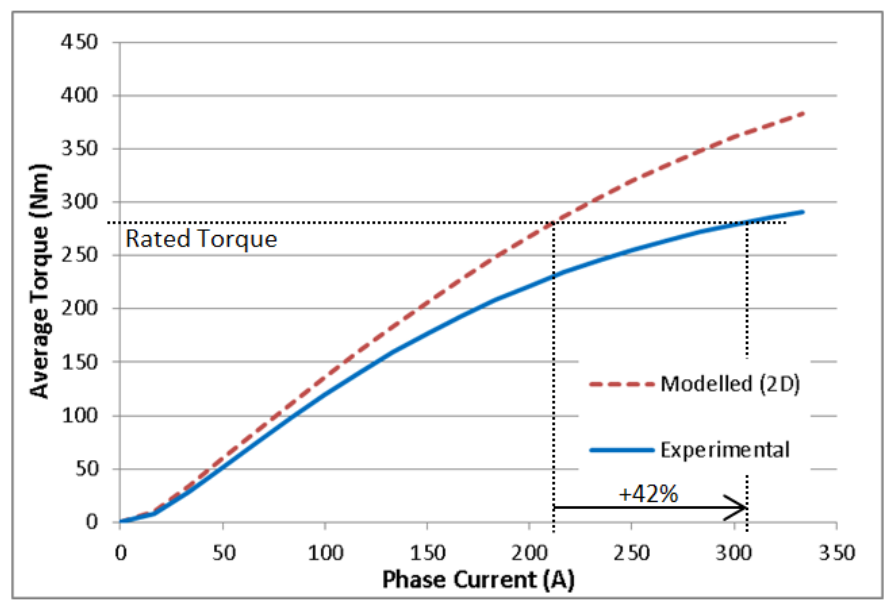

Fig. 16: Calculated Average Torque capability for the Prototype Motor and Optimised Motor (SRMSRM4).

\section{CONCLUSIONS}

Segmental Rotor SRMs are challenging to optimise because of their non-linear behaviour. The methodology presented in the paper has combined static and transient finite element model runs in order to allow a comprehensive optimisation of these machines.

Static runs have been used to estimate the maximum performance of the motor, confirming that full power can be achieved at base speed. This approach has been shown to allow the development of a valid pass/fail criteria based on the required peak performance of the motor.

Static characteristics have also been used to develop estimated current waveforms which have then in turn be used to support a transient analysis of motor losses and therefore efficiency; these have also shown a good correlation with simulated PWM current control approach applied in 2D FE.

Whilst this optimisation approach has been found to take considerable computation time (between 5 and 15 days per run), it is nevertheless significantly faster and more reliable than methods based on fully dynamic analysis alone. Whilst slower than techniques based solely on static FE calculations, it is more robust as it allows an assessment of both copper and iron losses as well as taking full account of magnetic interactions between phases.

Validation of the optimisation approach, both through the use of finite element based analysis and also through prototype validation, has shown that the Segmental Rotor SRM optimisation approach has potential, but requires further improvement to increase its accuracy. The thermal performance of the motor needs to be considered, with machines having excessively high winding loss to be disregarded by the optimiser. Whilst significant allowance has been made for 3D effects, other factors including more accurate material characteristics and the impact of rotor segment fixing also need to be considered when estimating motor torque. Finally, the discrepancy between predicted and actual electrical steel performance, in the saturation region, needs to be understood and accounted for.

However, even taking into account the observations above, optimisation has shown that Segmental Rotor SRMs can produce performance equivalent to a class leading IPM. Although practical machines are expected to be $30 \%$ larger, they offer similar mass and the potential to be significantly cheaper, requiring no rare earth magnets and operating with a power converter of the same VA rating as that used with a permanent magnet machine.

\section{REFERENCES}

Dorrell, D.G., Knight, A.M., et al., "Comparison of different motor design drives for hybrid electric vehicles," in Energy Conversion Congress and Exposition (ECCE), 2010 IEEE, 2010, pp. 33523359.

[2] Neudorfer, H., Wicker, N., et al., "Comparison of three different electric powertrains for the use in hybrid electric vehicles," in Power Electronics, Machines and Drives, 2008. PEMD 2008. 4th IET Conference on, 2008, pp. 510-514.

[3] Zhu, Z.Q. and Chan, C.C., "Electrical machine topologies and technologies for electric, hybrid, and fuel cell vehicles," in Vehicle Power and Propulsion Conference, 2008. VPPC '08. IEEE, 2008, pp. 1-6.

[4] Sato Y., I.S., Okubo T., Abe M. and Tamai K., "Development of High Response Motor and Inverter System for the Nissan LEAF Electric Vehicle," presented at the SAE 2011 World Congress \& Exhibition, Detroit, Michigan, United States, 2011. Mecrow, B.C., El-Kharashi, E.A., et al., "Segmental rotor switched reluctance motors with single-tooth windings," Electric Power Applications, IEE Proceedings -, vol. 150, pp. 591-599, 2003.

[6] Mecrow, B.C., Finch, J.W., et al., "Switched reluctance motors with segmental rotors," Electric 
Power Applications, IEE Proceedings -, vol. 149, pp. 245-254, 2002.

[7] Chen, X., Deng, Z., et al., "New designs of switched reluctance motors with segmental rotors," presented at the PEDM 2010, Brighton, UK, 2010.

[8] Oyama, J., Higuchi, T., et al., "The fundamental characteristics of novel switched reluctance motor with segment core embedded in aluminum rotor block," in Electrical Machines and Systems, 2005. ICEMS 2005. Proceedings of the Eighth International Conference on, 2005, pp. 515-519 Vol. 1.

[9] Vandana, R., Vattikuti, N., et al., "A Novel High Power Density Segmented Switched Reluctance Machine," in Industry Applications Society Annual Meeting, 2008. IAS '08. IEEE, 2008, pp. 1-7.

[10] Vattikuti, N., Rallabandi, V., et al., "A novel high torque and low weight segmented switched reluctance motor," in Power Electronics Specialists Conference, 2008. PESC 2008. IEEE, 2008, pp. 1223-1228.

[11] Widmer, J.D. and Mecrow, B.C., "Optimised Segmental Rotor Switched Reluctance Machines with a Greater Number of Rotor Segments than Stator Slots," IEEE Transactions on Industry Applications, 2013.

[12] Miller, T.J.E., Switched Reluctance Motors and their Control. Oxford: Magna Physics Publications Oxford University Press, 1993.

[13] Neittaanmaki, P., Rudnicki, M., et al., Inverse Problem and Optimal Design in Electricity and Magnetism: Oxford University Press, 1996.

[14] Hargreaves, P.A., Mecrow, B.C., et al., "Calculation of Iron Loss in Electrical Generators Using FiniteElement Analysis," Industry Applications, IEEE Transactions on, vol. 48, pp. 1460-1466, 2012.

[15] Wenbin Song, A.K., Janet Rees, Atul Bhaskar, Steven Bagnall, "Turbine blade fir-tree root design optimisation using intelligent $\mathrm{CAD}$ and finite element analysis," Computers and Structures, vol. 80, pp. 1853-1867, 2002.

[16] Boldea, I., Tutelea, L.N., et al., "Automotive Electric Propulsion Systems With Reduced or No Permanent Magnets: An Overview," Industrial Electronics, IEEE Transactions on, vol. 61, pp. 5696-5711, 2014.

[17] Takeno, M., Chiba, A., et al., "Test Results and Torque Improvement of the $50-\mathrm{kW}$ Switched Reluctance Motor Designed for Hybrid Electric Vehicles," Industry Applications, IEEE Transactions on, vol. 48, pp. 1327-1334, 2012. 